\title{
BMJ Open Investigation of the relationship between patient empowerment and glycaemic control in patients with type 2 diabetes: a cross-sectional analysis
}

\author{
Maire Fitzgerald, ${ }^{1}$ Colm O'Tuathaigh, ${ }^{1}$ Joe Moran ${ }^{2}$
}

To cite: Fitzgerald M, O'Tuathaigh C, Moran J. Investigation of the relationship between patient empowerment and glycaemic control in patients with type 2 diabetes: a cross-sectional analysis. BMJ Open 2015;5: e008422. doi:10.1136/ bmjopen-2015-008422

- Prepublication history for this paper is available online. To view these files please visit the journal online (http://dx.doi.org/10.1136/ bmjopen-2015-008422).

Received 7 April 2015 Revised 28 September 2015 Accepted 30 October 2015

CrossMark

\begin{abstract}
${ }^{1}$ School of Medicine, University College Cork, Cork, Ireland

${ }^{2}$ Department of General

Practice, University College Cork, Cork, Ireland
\end{abstract}

Correspondence to

Dr Joe Moran;

j.moran@ucc.ie

\author{
ABSTRACT \\ Objective: To determine whether there is an \\ association between patient empowerment and \\ diabetes management in terms of the primary \\ outcomes of metabolic control as measured by \\ glycaemic control (glycated haemoglobin, HbA1c), \\ high-density lipoprotein (HDL), low-density lipoprotein \\ (LDL), total cholesterol (TC) and triglycerides. \\ Design: Retrospective cross-sectional analysis \\ conducted in 2012.
}

Setting: Data from Diabetes Federation of Ireland from participants enrolled in the Community Orientated Diabetes Education (CODE) Programme.

Participants: 569 patients diagnosed with type 2 diabetes.

Exposures: Patient empowerment levels, as measured by the Diabetes Empowerment Scale-Short Form. Additional information collected included patients' gender, age, body mass index (BMI), smoking status and number of years with diabetes.

Outcome measures: HbA1c, HDL, LDL, TC and triglycerides values.

Results: Partial correlation analyses failed to show any statistically significant relationship between patient empowerment and glycaemic control or other diabetes management variables (HbA1c, $p=0.32$; $H D L, p=0.95$; LDL, $p=0.77 ; \mathrm{TC}, p=0.49$; triglycerides, $p=0.77$ ). Logistic regression analysis confirmed that patient empowerment score was not a significant predictor of level of glycaemic control. Time since diagnosis of diabetes was associated with increased $\mathrm{HbA1c}$ levels. Age and gender were significant predictors of $\mathrm{HDL}$ and LDL levels, while gender and age were associated with changes in TC and triglycerides levels, respectively.

Conclusions: No significant association was found between patient empowerment levels and other measures of diabetes control in this study. Further research into the short-term and long-term outcomes of the empowerment model, at different levels of disease management, and across different settings, is required to evaluate its value in the management of patients with diabetes.

\section{INTRODUCTION}

Type 2 diabetes mellitus (T2DM) is a challenging global public health problem. ${ }^{1}$

\section{Strengths and limitations of this study}

- Using a validated diabetes self-management instrument, and a large and geographically varied Irish type 2 diabetes mellitus patient population, we have demonstrated a lack of association between patient empowerment levels and glycaemic control.

- Employing a biochemical measure of glycaemic control, as well as analysis of lipid profiles, this study demonstrates no direct linear relationship between patient empowerment and improved diabetes management.

- As our sample consisted of participants enrolled in the Community Orientated Diabetes Education (CODE) programme, the study population was very familiar with diabetes management, and this may have contributed to volunteer bias in our sample.

- The present study employed a cross-sectional design, precluding any temporal or causal inferences regarding relationships.

In 2007 there was an estimated 144000 adults with diabetes in Ireland, and by 2020 the total estimate is predicted to raise to over 233 000. ${ }^{2}$ Across Europe, T2DM accounts for over $85 \%-90 \%$ of all diabetes cases. $^{3}$ Diabetes mellitus is associated with long-term microvascular and macrovascular complications such as cardiovascular disease, retinopathy, nephropathy and neuropathy. ${ }^{3}$ Glycaemic control is key to reducing complications and decreasing morbidity and mortality in patients with diabetes. ${ }^{4}$ For every $1 \%$ increase in glycated haemoglobin (HbAlc), the risk of a diabetes-related complication increases by $21 \%$ in patients with T2DM. ${ }^{5}$ However, low and high HbAlc values have been associated with increased mortality and cardiac events, indicative of a non-linear relationship between HbA1c levels and cardiovascular disease risk in T2DM. ${ }^{6}$ It is known that fewer than $20 \%$ of patients diagnosed with 
T2DM meet recommended targets for glycaemic, lipid and blood pressure control. ${ }^{4}$

The serious and chronic nature of diabetes, the complexity of its management and the multiple daily self-care decisions made by patients with diabetes, contribute to the ongoing challenge of adhering to a lifelong predetermined diabetes care programme. Intervention strategies that empower patients to set goals, make wellinformed decisions on therapeutic options, and assume responsibility for their daily diabetes care, help patients deal to improve their diabetes care. ${ }^{7-9}$

Patient empowerment is defined as 'a process whereby patients have the knowledge, skills, attitudes and selfawareness necessary to influence their own behaviour and that of others in order to improve the quality of their lives. ${ }^{10}$ Factors related to empowerment including readiness to change or commitment to adherence to disease management guidelines have been reported to be responsible for $95 \%$ of the fluctuation over time in HbAlc levels. ${ }^{11}$ Empowerment education centres on providing patients with the knowledge to make informed decisions in order to improve their quality of life. A number of structured and diabetes-specific educational programmes have been described. ${ }^{12-16}$ These focus on teaching the empowerment philosophy in a culturally specific way, based on learning by problem solving; these include X-PERT, DESMOND, CODE and ORLA. ${ }^{12}$ Empowerment-based self-management interventions have been widely used in patients with T2DM. ${ }^{13-16}$ These programmes share a patient-centred approach and partnership, self-awareness and self-motivation, selfcare or self-management, problem solving and reflection concepts. ${ }^{16-19}$ However, the overall effectiveness of these different programmes in patients with T2DM varies considerably. ${ }^{1}$

Empowerment assumes that changes in self-efficacy correspond with improvements in health and clinical outcomes. ${ }^{20}$ It is assumed that increased empowerment in patients with T2DM results in increased motivation to make better self-management decisions on a daily basis. Greater disease management, in turn, leads to less dependence on healthcare services and therefore a more cost-effective use of healthcare resources. However, studies which have looked at the relationship between patient empowerment, as measured across several available psychometric measures, and metabolic outcomes in patients with T2DM, have reported inconsistent results. In 1995, Anderson et $a l^{7}$ first reported that empowerment had a significant and positive effect on metabolic control and quality of life outcomes in patients with T2DM. However, in a subsequent study reported by the same group, they failed to replicate the positive association between empowerment and metabolic outcome measures including HbAlc levels. ${ }^{21}$ Subsequent research has provided conflicting results concerning the putative benefits of empowerment on metabolic outcomes in patients with T2DM with some reporting benefits, ${ }^{22-24}$ and other studies reporting weak or non-existent effects. ${ }^{25}$ Additionally, a recently published meta-analysis of 17 studies concluded that there is no correlation between locus of control, a psychological construct which has been related to empowerment, ${ }^{26}$ and glycaemic outcome. ${ }^{27}$

The aim of this study was to evaluate the correlation between patients' empowerment and diabetes metabolic control, as measured by HbA1c, HDL, LDL, total cholesterol (TC) and triglycerides.

\section{METHODS}

\section{Study design}

The present data were collected by the Diabetes Federation of Ireland from participants enrolled in the Community Orientated Diabetes Education (CODE) Programme in 2012. The CODE programme is a national structured diabetes education programme available to patients with T2DM, who are either recently diagnosed or have been diagnosed for several years, throughout the Republic of Ireland. It is partly funded by the Health Service Executive (HSE) in Ireland and is delivered at local level by trained healthcare professionals. Data collected at baseline for patients enrolled in this programme were investigated in the present study; data collection started prior to the start of the educational intervention. The variables included were as follows: demographic information, diabetes care location, method of diabetes management, body mass index (BMI), Diabetes Empowerment Questionnaire-Short Form $^{21}$ score. In addition, practise-based blood HbAlc, high-density lipoprotein (HDL), low-density lipoprotein (LDL), TC and triglycerides were recorded. Ethical approval was obtained from the Clinical Research Ethics Committee of the Cork Teaching Hospitals.

\section{Diabetes Empowerment Questionnaire-Short Form (DES-SF)}

The Diabetes Empowerment Scale is a measure of psychosocial self-efficacy, specifically developed for a diabetes patient population. ${ }^{28}$ Since the development of the original questionnaire in 2000, subsequent versions have seen the number of items reduced from 37 to 28 items, and eventually to eight items, where the latter is known as the short form version (DES-SF; 21). The eight item short form DES can be used to provide a brief overall assessment of diabetes-related psychosocial self-efficacy. The DES-SF was created by choosing the statements with the highest item to subscale correlation from the original questionnaire in $2000 .{ }^{21}$ The internal consistency of the DES-SF, as measured by Cronbach's $\alpha$, was 0.84 , providing evidence that the DES-SF represents a valid and reliable measure of diabetes related psychosocial self-efficacy. ${ }^{21}$ In the DES-SF, participants are asked to indicate their agreement to eight individual statements about their own ability to manage diabetes. Agreement can range from 'strongly agree' to 'strongly disagree'. Possible scores are 1 to 5 for each statement 
or for the total score with higher numbers indicating more empowered people.

\section{Data analysis}

Data were extracted from the Diabetes Federation of Ireland CODE database from 2012. All statistical analyses were completed using SPSS V.20 (IBM, New York, New York, USA). Summary statistical analysis was completed for categorical and non-categorical variables. Partial correlation analysis was used to establish associations between empowerment scores and HbAlc, HDL, LDL, cholesterol, and triglycerides, while controlling for the number of years with diabetes (log-transformed), age group, gender, smoking status and BMI. Binary logistic regression was employed to examine the influence of several categorical and continuous scale independent variables (empowerment, gender, age, medication regimen (two categories: use versus non-use of insulin), years with a T2DM diagnosis) on glycaemic control. Glycaemic control was presented as a two-level categorical variable: adequate glycaemic control $(\mathrm{HbA} 1 \mathrm{c} \leq 7 \%)$; inadequate glycaemic control (HbA1c $>7 \%$; reference category). An additional logistic regression analysis was conducted using the same set of independent and outcome measures, except for empowerment, which was recoded as a categorical variable on the basis of 'low' $(<3)$ and 'high' (>3) DES-SF scores, as described in the literature. ${ }^{21}$ Multivariable linear regression analyses were conducted to examine the influence of categorical and continuous scale independent variables (empowerment, gender, age, medication regimen and years with a T2DM diagnosis) on each of the following metabolic outcome measures: HDL, LDL, triglycerides and cholesterol. Additional analyses involved univariate comparisons of metabolic outcome levels according to gender, recategorised BMI (4 levels: underweight $(<18.5)$, normal (18.5-25.0), overweight $(25-30)$, obese $(>30))$, using $\mathrm{t}$ tests or one-way analysis of variance, with Bonferroni post hoc comparisons where appropriate. For all analyses, a $p$ value $<0.05$ was considered statistically significant.

\section{RESULTS}

Table 1 provides a summary of the demographic and clinical characteristics of the study population (patients with T2DM, $n=569$ ). The majority of the study population was male $(58.2 \%)$, and belonged in the 60-69-year age group $(\mathrm{n}=119)$. Participants ranged from newly diagnosed to living with diabetes for 50 years; mean duration of diabetes for the overall sample was 5.5 years $(\mathrm{SD}=5.3)$. The majority of patients sampled $(\mathrm{n}=396,70 \%)$ are being treated with oral hypoglycaemic agents, $16 \%$ $(n=89)$ on no diabetes medications or on insulin only $(\mathrm{n}=57,10 \%)$.

The mean total empowerment score was $3.9(\mathrm{SD}=0.7)$ indicating a moderate-to-high belief in their ability to self-manage diabetes. More participants reported being
Table 1 Demographic and clinical characteristics of the sample population

T2DM $(n=569)$

\begin{tabular}{|c|c|}
\hline \multicolumn{2}{|l|}{ Age } \\
\hline Range & $23-87$ \\
\hline Mean (SD) & $62.9(10.5)$ \\
\hline \multicolumn{2}{|l|}{$\operatorname{Sex}(n, \%$ of total $n)$} \\
\hline Male & $332(58.2)$ \\
\hline \multicolumn{2}{|c|}{ Diabetes treatment $(n, \%$ of total $n)$} \\
\hline No treatment & $89(16.0)$ \\
\hline Oral medications & $396(69.0)$ \\
\hline Insulin & $57(10.0)$ \\
\hline Not known & $31(5.0)$ \\
\hline \multicolumn{2}{|c|}{ Source of diabetes care ( $\%$ of total $n$ ) } \\
\hline Hospital & $78(14.0)$ \\
\hline Primary care & $287(50.0)$ \\
\hline Hospital and primary care & $173(30)$ \\
\hline Unanswered & $35(6)$ \\
\hline \multicolumn{2}{|l|}{ Years with diabetes } \\
\hline Range & $0-50$ \\
\hline Mean (SD) & $5.5(5.3)$ \\
\hline \multicolumn{2}{|l|}{ Smoking status $\mathrm{n}$ (\% of total $\mathrm{n}$ ) } \\
\hline Smoking & $60(10.5)$ \\
\hline \multicolumn{2}{|l|}{ Empowerment score } \\
\hline Range & $1-5$ \\
\hline Mean (SD) & $3.9(0.7)$ \\
\hline
\end{tabular}

T2DM, type 2 diabetes mellitus.

well-empowered (scores 4.0-5.0, 38\% of total sample) than poorly empowered (scores 1.0-3.9, 32\% of total sample).

Table 2 summarises the blood test results with mean values for each of the metabolic outcome measures for the entire study population.

\section{Partial correlation analyses}

Partial correlation was used to explore the relationship between empowerment and HbAlc while controlling for age, smoking status, years with diabetes, gender and BMI. There was no statistically significant association between empowerment scores and HbAlc levels ( $p=0.32$; see table 2 for summary of correlational analyses). Similarly no statistical significance was observed between empowerment scores and HDL $(p=0.95)$, LDL $(\mathrm{p}=0.77)$, triglycerides $(\mathrm{p}=0.77)$ or cholesterol levels $(\mathrm{p}=0.49)$.

\section{Univariate comparisons}

Comparisons using $t$ test revealed several gender-related differences, with females demonstrating significantly higher HDL (females vs males, average scores: 1.29 vs $1.12 ; \mathrm{t} 431=4.29, \mathrm{p}<0.0001$ ), but lower LDL (females versus males, average scores: 2.21 vs $2.50 ; \mathrm{t}{ }_{428}=3.26$, $\mathrm{p}<0.01$ ), and cholesterol (females vs males, average scores: 4.05 vs $\left.4.58 ; \mathrm{t}{ }_{457}=5.58, \mathrm{p}<0.0001\right)$ levels than male patients. No gender differences were observed in relation to empowerment scores or any other outcome 
Table 2 Glycaemic control and metabolic marker values and their correlation with empowerment scores

\begin{tabular}{llllll}
\hline & Mean result & Range & SD & R value & p Value \\
\hline $\mathrm{HbA1C}$ & 7.05 & $4.50-13.20$ & 1.30 & 0.06 & 0.32 \\
$\mathrm{HDL}$ & 1.20 & $0.40-3.90$ & 0.41 & 0.01 & 0.95 \\
$\mathrm{LDL}$ & 2.34 & $0.60-6.80$ & 0.92 & 0.02 & 0.77 \\
Triglycerides & 1.70 & $0.40-9.90$ & 1.02 & 0.02 & 0.77 \\
Cholesterol & 4.27 & $2.20-8.70$ & 1.06 & 0.04 & 0.49 \\
\hline
\end{tabular}

$R$ value denotes the partial correlation coefficient.

$\mathrm{HbA1c}$, glycated hemoglobin; HDL, high-density lipoprotein; LDL, low-density lipoprotein.

measure (all $\mathrm{p}>0.05)$. Statistical comparison of recategorised BMI groups ('underweight', 'normal', 'overweight', 'obese') in relation to each of the outcome measures revealed that 'obese' patients demonstrated lower levels of the following outcome measures relative to other BMI groups: HDL ( $\mathrm{F}_{2,417}=8.58, \mathrm{p}<0.01$; Bonferroni comparisons, all $\mathrm{p}<0.01)$; triglycerides $\left(\mathrm{F}_{2}, 415=5.88, \mathrm{p}<0.01\right.$; Bonferroni comparisons, all $\mathrm{p}<0.05)$. In contrast, only the 'overweight' group displayed reduced HbA1c levels relative to other BMI categories $\left(\mathrm{F}_{2,447}=4.57, \mathrm{p}<0.05\right.$; Bonferroni comparisons, all $\mathrm{p}<0.05)$.

\section{Binary logistic and multiple linear regression analyses}

To clarify the factors affecting glycaemic control and diabetes management outcome variable levels, binary logistic regression was carried out using five demographic and clinical variables (empowerment score, years with diabetes, age, gender, medication regimen), and where the binary categorical outcome variable was glycaemic control (see table 3). An alternative logistic regression analysis where empowerment was recoded as a two-level categorical variable (DES-SF score $<3$, DES-SF score $>3$ ) similarly failed to demonstrate any significant effect of empowerment on glycaemic control $(\mathrm{p}=0.56$; data not shown). Multiple linear regression analysis was performed using the same five demographic and clinical

Table 3 Results of binary logistic regression modelling for prediction of glycaemic control

\begin{tabular}{lrlll}
\hline Independent variable & \multicolumn{1}{l}{$\mathbf{B}$} & $\mathbf{S E}$ & $\mathbf{p}$ Value & $\mathbf{R}^{\mathbf{2}}$ \\
\hline HbA1c† & & & & \\
Empowerment & 0.03 & 0.19 & 0.86 & $0.17 \ddagger$ \\
Years with diabetes & 1.86 & 0.36 & $0.001^{\star \star}$ & \\
Age & -0.01 & 0.01 & 0.39 & \\
Gender & -0.23 & 0.27 & 0.39 & \\
Medication regimen§ & -0.54 & 0.42 & 0.20 & \\
\hline
\end{tabular}

$\beta$ denotes the standardised variable estimate.

SE denotes the SE of the variable estimate.

${ }^{* *} \mathrm{p}<0.01$.

†Categorical variable, two levels: inadequate glycaemic control ( $\mathrm{HbA} 1 \mathrm{c}>7 \%$; reference category), adequate glycaemic control (HbA1c $\leq 7 \%$ ).

$\ddagger$ Nagelkerke $R^{2}$ estimate, which denotes the proportion of the variance explained by the model.

$\S$ Categorical variable, two levels: non-use of insulin treatment (reference category), use of insulin treatment.

$\mathrm{HbA1c}$, glycated haemoglobin. variables used in the logistic regression analysis as independent variables and four outcome variables related to diabetes management (HDL, LDL, triglycerides, cholesterol; see table 4). Diabetes duration was associated with higher HbAlc levels in patients with T2DM. Increasing age was associated with higher HDL levels. Conversely, as patients increased in age, they demonstrated reduced LDL and triglycerides levels. Females showed higher HDL and lower cholesterol levels.

\section{DISCUSSION}

This is the first study which has examined the relative predictive relationship between self-reported baseline empowerment and metabolic outcomes in a CODE

Table 4 Results of multiple linear regression modelling for prediction of disease management variables

\begin{tabular}{|c|c|c|c|c|}
\hline Independent variable & B & SE & p Value & $\mathbf{R}^{2}$ \\
\hline \multicolumn{5}{|l|}{ HDL } \\
\hline Empowerment & -0.01 & 0.03 & 0.94 & \multirow[t]{5}{*}{0.09} \\
\hline Years with diabetes & 0.05 & 0.05 & 0.42 & \\
\hline Age & 0.21 & 0.01 & $0.001^{\star *}$ & \\
\hline Gender & 0.20 & 0.04 & $0.001^{* *}$ & \\
\hline Medication regimen & 0.09 & 0.07 & 0.14 & \\
\hline \multicolumn{5}{|l|}{ LDL } \\
\hline Empowerment & -0.04 & 0.08 & 0.54 & \multirow[t]{5}{*}{0.06} \\
\hline Years with diabetes & -0.06 & 0.13 & 0.39 & \\
\hline Age & -0.18 & 0.01 & $0.005^{\star *}$ & \\
\hline Gender & 0.12 & 0.11 & $0.05^{\star}$ & \\
\hline Medication regimen & -0.03 & 0.17 & 0.62 & \\
\hline \multicolumn{5}{|l|}{ Triglycerides } \\
\hline Empowerment & 0.05 & 0.10 & 0.43 & \multirow[t]{5}{*}{0.02} \\
\hline Years with diabetes & 0.01 & 0.18 & 0.99 & \\
\hline Age & -0.13 & 0.01 & $0.04^{*}$ & \\
\hline Gender & 0.03 & 0.14 & 0.60 & \\
\hline Medication regimen & 0.01 & 0.22 & 0.85 & \\
\hline \multicolumn{5}{|l|}{ Cholesterol } \\
\hline Empowerment & 0.03 & 0.08 & 0.61 & \multirow[t]{5}{*}{0.09} \\
\hline Years with diabetes & -0.18 & 0.15 & 0.22 & \\
\hline Age & -0.09 & 0.01 & 0.13 & \\
\hline Gender & 0.25 & 0.12 & $0.001^{\star *}$ & \\
\hline Medication regimen & 0.05 & 0.19 & 0.40 & \\
\hline
\end{tabular}

Adjusted $R^{2}$ denotes the adjusted proportion of the variance explained by the model.

$\beta$ denotes the standardised variable estimate.

SE denotes the SE of the variable estimate.

${ }^{*} p<0.05,{ }^{* *} p<0.01$.

HDL, high-density lipoprotein; LDL, low density lipoprotein. 
cohort of patients with T2DM. The main findings in the present study were that empowerment, as measured by patient responses in the DES-SF questionnaire, was found to be unrelated to glycaemic control (HbAlc) or other disease-related outcomes (HDL, LDL, triglycerides, cholesterol). With respect to glycaemic control, this finding was consistent with previous reports that DES scores and HbAlc levels vary independently of each other. ${ }^{21}$

\section{Patient empowerment}

The mean DES-SF score across patients with T2DM was 3.85 , which is indicative of a moderate-to-high level of empowerment in their ability to manage their condition. On the DES-SF scale, a score of 3.0 is a neutral point, whereas a score of 2.0 or less indicates that the person is not handling life with diabetes in an empowered way. The values reported in the current study are consistent with values reported for a previous CODE study in $2011,{ }^{29}$ and are higher than the average scores reported by Deakin et al (mean DES-SF-2.9. $9^{15}$ ) and Sigurdardottir and Jonsdottir (mean DES-SF-3.68 ${ }^{19}$ ). When comparing DES-SF scores across between study populations, it is important to take into account the effect of culture, educational status and socioeconomic factors on baseline empowerment scores. In contrast with previous reports, the current study did not demonstrate any gender differences in the DES-SF score profile of patients with T2DM.

\section{Glycaemic control}

The present study found that the mean HbAlc (7.05\%) level in this cohort of patients was marginally outside of the recommended range for patients with T2DM $(<7.0 \%){ }^{30}$ This finding was partially consistent with research carried out by the Diabetes In General Practice Group, ${ }^{31}$ HSE Diabetes Structured Care Programme ${ }^{32}$ and the National Audit in England, ${ }^{33}$ where average HbA1c values recorded in patients with T2DM were above the recommended target. These findings highlight that for a significant proportion of patients with T2DM sampled in this study $(39.8 \%)$, their glycaemic control levels were not in line with recommended care targets, which points towards increased risk of diabetes related complications in a subset of this patient sample. However, there is ongoing debate within the field regarding optimal targets for $\mathrm{HbAlc}$, where increased and decreased levels are associated with adverse health outcomes in patients with T2DM. ${ }^{6}$ Consistent with other studies, years with a T2DM diagnosis was associated with an increase in HbA1c levels, indicative of poorer glycaemic control ${ }^{3435}$ this may be attributable to increased resistance to medication and the need for higher doses or additional medications over time. ${ }^{36}$

\section{Other disease management markers}

The mean cholesterol level $(4.27 \mathrm{mmol} / \mathrm{L})$ reported for patients in the present study fell below the recommended national targets for TC $(<4.5 \mathrm{mmol} / \mathrm{L}){ }^{4}$ Therefore, the majority of participants in this study population were achieving the target for TC level, which is a positive outcome given that cardiovascular risk is high among patients with T2DM. This was in keeping with findings from the CODE programme in $2010^{29}$ and Diabetes In General Practice Group, ${ }^{31}$ HSE Diabetes Structured Care Programme ${ }^{32}$ and the National Audit in England. ${ }^{33}$ It was also demonstrated that when patients were stratified based on BMI category, cholesterol levels increased in the following category-dependent fashion: normal <overweight <obese. The findings of this study show that the mean HDL level was $1.20 \mathrm{mmol} / \mathrm{L}$ in this patient sample; this value is consistent with the national recommended target of $>1 \mathrm{mmol} / \mathrm{L}$. Similarly, the mean LDL level was $2.34 \mathrm{mmol} / \mathrm{L}$, which is within the recommended target range $(<2.5 \mathrm{mmol} / \mathrm{L})$. The patients with T2DM studied in this sample population were on target for mean cholesterol, HDL and LDL, but this trend was reversed for triglyceride levels $(4.27 \mathrm{mmol} / \mathrm{L})$. The mean triglyceride level $(4.27 \mathrm{mmol} / \mathrm{L})$ in the current patient cohort lies considerably outside of the recommended goal for triglyceride levels $(<2.0 \mathrm{mmol} / \mathrm{L})$. Tight lipid control is important in reducing the risk of cardiovascular events therefore a greater percentage of these patients should be reviewed in order to meet the target range for triglycerides. Male patients displayed lower cholesterol, HDL and LDL levels compared to females, which is consistent with previous reports in patients with T2DM. ${ }^{37}$ These gender differences have been discussed in the context of elevated risk of cardiovascular disease among female versus male patients with T2DM, and appear to be attributable to the complex interplay of physiological, treatment and psychological factors. ${ }^{38}$ Among the variables which predicted changes across these outcome measures in patients with T2DM, duration of diabetes emerged a significant independent predictor of TC and LDL levels, with increased years since diagnosis (independently of age) associated with increased values for both measures.

\section{Empowerment and glycaemic control-implications of current research}

When considered against the backdrop of numerous intervention-based studies which have identified empowerment as a key modifier of health outcomes in patients with T2DM, these findings suggest the possibility of a non-linear and complex relationship between the empowerment construct and maintenance of good metabolic control. This possibility is supported by data from a number of structured diabetes education programmes, aimed at encouraging self-help, which have been shown to be associated with only limited benefits in glycaemic control, but significant educational and psychological benefits. ${ }^{14}$ It has been noted that many previous diabetes educational intervention studies have been short-term only, when improvements may be simply related to non-specific support and interest from health 
professionals, while longitudinal studies are difficult to interpret, as education was combined with integrated systems of intensified pharmacological treatment. ${ }^{14}$ The current data also raise questions about the relationship between the concept of empowerment in T2DM, in theory and practise. It has been suggested that an important methodological challenge in the field involves different operational definitions of empowerment employed in studies examining the efficacy of empowerment-based self-management interventions in T2DM. ${ }^{39}$ Empowerment has been generally described as a poorly defined construct, with generic and conditionspecific patient empowerment self-report measures capturing different constructs and/or limited conceptualisations of empowerment. ${ }^{39}$ Additionally, the variable impacts and outcomes reported by studies examining the efficacy of empowerment-based self-management may also reflect the absence of a theoretical approach to optimising health-related behavioural change as part of case management. This unsatisfactory situation has resulted in a 'black box' problem, where the necessary and sufficient conditions for change to occur are unknown. ${ }^{40}$

\section{Strengths and limitations}

Using a validated diabetes self-management instrument, and a large and geographically varied Irish T2DM patient population, we have demonstrated a lack of association between patient empowerment levels and glycaemic control. A limitation of this study concerns the representativeness of the study sample. Time with diabetes was, on average, 5.5 years and only $10 \%$ of the patients used insulin. Therefore, most patients were in the initial stages of T2DM. In those participants, it might be argued that empowerment issues will play a less crucial role on maintenance of glycaemic control, since adequate glycaemic levels are relatively easy to achieve with one or two oral medications. It is also reasonable to propose that empowerment may play a more significant role during the advanced stages of the disease (not adequately represented in this study). Researchers have also questioned the sensitivity of existing empowerment scales (such as the DES-SF) in capturing a multilevel construct like empowerment, noting that the DES-SF has also not been evaluated for test-retest reliability or responsiveness to change. ${ }^{41}$ Lastly, the cross-sectional design limits the assessment of causality.

\section{CONCLUSION}

The results from this research suggest that empowerment, as measured by the DES-SF, has no direct impact on metabolic control in patients with T2DM. Healthcare providers should be aware that there is little evidence to show a direct linear relationship between patient empowerment and improved glycaemic control. ${ }^{21}$ Differential sensitivity of various measures of empowerment may account for elements of patient empowerment which are not appreciated in the current models. Ongoing debate regarding the theoretical nature of the concept is a factor which has contributed to the lack of applicability of the empowerment construct in a clinical setting. Further research into the short-term and long-term outcomes of the empowerment model, in different levels of disease management, and across different settings, is required to illuminate its value in diabetes management. In an Irish and European context, the next decade will be characterised by a considerable increase in the number of patients with T2DM being treated in a primary care setting. ${ }^{42}$ In the management of chronic disease like T2DM, the role of the general practitioner is gradually shifting from performing services to advising patients on effective selfmanagement. Recent evidence has demonstrated a J-shaped relationship between HbAlc and all-cause mortality in patients with T2DM. ${ }^{43}$ In this context, a personalised medicine approach to managing glycaemic control in T2DM, which takes into account the potentially adverse of effects of glucose-lowering drugs, as well as various comorbidities (especially those which are age-related), is important. ${ }^{30}$ Many patients are still not achieving the recommended diabetes targets, and further research into the factors that underlie the management of diabetes is necessary in order to improve patient outcomes.

Contributors MF designed data collection tools, collected the study data, wrote the statistical analysis plan, cleaned the data and drafted the paper. CO'T analysed the data and drafted and revised the paper. JM designed data collection tools, monitored data collection during the study, and revised the draft paper. He is guarantor. All authors approved the final version of the article to be submitted and published.

Funding This research received no specific grant from any funding agency in the public, commercial or not-for-profit sectors.

Competing interests None declared.

Ethics approval Ethical approval was obtained from the Clinical Research Ethics Committee of the Cork Teaching Hospitals (Ref. ECM4(ii)09/01/2013). The study was exempt from consent requirements as the data meet the requirement for de-identification as defined by Clinical Research Ethics Committee of the Cork Teaching Hospitals.

Provenance and peer review Not commissioned; externally peer reviewed.

Data sharing statement No additional data are available.

Open Access This is an Open Access article distributed in accordance with the Creative Commons Attribution Non Commercial (CC BY-NC 4.0) license, which permits others to distribute, remix, adapt, build upon this work noncommercially, and license their derivative works on different terms, provided the original work is properly cited and the use is non-commercial. See: http:// creativecommons.org/licenses/by-nc/4.0/

\section{REFERENCES}

1. Funnell MM, Anderson RM. Empowerment and self-management of diabetes. Clin Diabetes 2004;22:123-7.

2. Balanda KP, Barron S, Fahy L, et al. Making chronic conditions count: hypertension, stroke, coronary heart disease, diabetes. A systematic approach to estimating and forecasting population prevalence on the island of Ireland. Dublin: Institute of Public Health in Ireland, 2010. 
3. Forouhi NG, Wareham NJ. The EPIC-InterAct Study: a study of the interplay between genetic and lifestyle behavioral factors on the risk of type 2 diabetes in of type 2 diabetes in European populations. Curr Nutr Rep 2014;3:355-63.

4. Harkins V. A practical guide to integrated type 2 diabetes care. Edited by: Irish College of General Practitioners, Health Service Executive, And Irish Endocrine Society. Dublin: Health Service Executive, 2008.

5. NICE Clinical Knowledge Summaries. Diabetes type 2. 2010. http:// www.patient.co.uk/doctor/diabetes-mellitus

6. Currie CJ, Peters JR, Tynan A, et al. Survival as a function of $\mathrm{HbA} 1 \mathrm{c}$ in people with type 2 diabetes: a retrospective cohort study. Lancet 2010;375:481-9.

7. Anderson RM, Funnell MM, Butler PM, et al. Patient empowerment: result of a randomized controlled trial. Diabetes Care 1995;18:943-9.

8. Wong CK, Wong WC, Lam CL, et al. Effects of Patient Empowerment Programme (PEP) on clinical outcomes and health service utilization in type 2 diabetes mellitus in primary care: an observational matched cohort study. PLoS ONE 2014;9:e95328.

9. Wong CK, Wong WC, Wan YF, et al. Patient Empowerment Programme in primary care reduced all-cause mortality and cardiovascular diseases in patients with type 2 diabetes mellitus: a population-based propensity-matched cohort study. Diabetes Obes Metab 2015;17:128-35.

10. Funnell MM, Anderson RM, Arnold MS, et al. Empowerment: an idea whose time has come in diabetes education. Diabetes Educ 1991;17:37-41.

11. Paterson B. Myth of empowerment in chronic illness. J Adv Nurs 2001;34:574-81.

12. Davies MJ, Heller S, Skinner TC, et al. Effectiveness of the diabetes education and self management for ongoing and newly diagnosed (DESMOND) programme for people with newly diagnosed type 2 diabetes: cluster randomised controlled trial. BMJ 2008;336:491-5.

13. Anderson RM, Funnell M, Aikens JE, et al. Evaluating the efficacy of an empowerment-based self-management consultant intervention: results of a two-tear randomized controlled trial. Therap Patient Educ 2009;1:3-11.

14. Cooper H, Booth K, Gill G. A trial of empowerment-based education in type 2 diabetes-Global rather than glycaemic benefits. Insulin 2009;4:61-7.

15. Deakin TA, Cade JE, Williams R, et al. Structured patient education: the diabetes X-PERT Programme makes a difference. Diabetes Medic 2006;23:944-54.

16. Naik AD, Teal CR, Rodriguez E, et al. Knowing the ABCs: a comparative effectiveness study of two methods of diabetes education. Patient Educ Couns 2011;82:1-7.

17. Anderson RM, Funnell MM, Nwankwo R, et al. Evaluating a problem-based empowerment program for African Americans with diabetes: results of a randomized controlled trial. Ethnic Dis 2005; 15:671-8.

18. Figar S, Galarza C, Petrlik E, et al. Effect of education on blood pressure control in elderly persons: a randomized controlled trial. Am $J$ Hypertens 2006;19:737-43.

19. Sigurdardottir AK, Jonsdottir H. Empowerment in diabetes care: towards measuring empowerment. Scand J Caring Sci 2008;22:284-91.

20. Lorig K, Holman H. Self-management education: history, definition, outcomes and mechanisms. Ann Behav Med 2003;26:1-7.

21. Anderson RM, Fitzgerald JT, Gruppen LD, et al. The Diabetes empowerment Scale-Short Form (DES-SF). Diabetes Care 2003;26:1641-2.

22. Tol A, Shojaeezadeh D, Sharifirad G, et al. Determination of empowerment score in type 2 diabetes patients and its related factors. J Pak Med Assoc 2012;62:16-20.
23. Chen MF, Tsai CT, Hsu SM, et al. Patient perceptions of empowerment processes, health outcomes and related factors in patients living with diabetes in Taiwan: a cross-sectional survey. J Community Health Nurs 2013;30:201-15.

24. Yang S, Hsue C, Lou Q. Does patient empowerment predict self-care behavior and glycosylated hemoglobin in Chinese patients with type 2 diabetes? Diabetes Technol Ther 2015;17:343-8.

25. Shiu AT, Li SM, Thompson DR. The concurrent validity of the Chinese version of the Diabetes Empowerment Scale. Diabetes Care 2005;28:498-9.

26. Ahola AJ, Groop PH. Barriers to self-management of diabetes. Diabetes Medic 2013;30:413-20.

27. Hummer K, Vannatta J, Thompson D. Locus of control and metabolic control of diabetes: a meta-analysis. Diabetes Educ 2011;37:104-10.

28. Anderson RM, Funnell MM, Fitzgerald JT, et al. The Diabetes empowerment scale: a measure of psychosocial self-efficacy. Diabetes Care 2000;23:739-43.

29. Diabetes Federation of Ireland 2011. Annual Report 2011. http:// www.diabetes.ie/wp-content/uploads/2011/09/Annual-Report-2011with-lay-summary-appendix.pdf

30. Inzucchi SE, Bergenstal RM, Buse JB, et al. Management of hyperglycemia in type 2 diabetes, 2015: a patient-centered approach. Update to a position statement of the American Diabetes Association and the European Association for the Study of Diabetes. Diabetes Care 2015;38:140-9.

31. Murphy K, McHugh S, Moran J. Diabetes in general practice audit report: technical report. Ireland: University College Cork, 2011.

32. Marsden P, Brennan C, McHugh S, et al. Audit report of the HSE Midland Diabetes Structured Care Programme. HSE, 2010. http:// hdl.handle.net/10147/110893

33. Health and Social Care Information Centre. National Diabetes Audit. Key findings about the quality of care for people with diabetes in England report. Audit period 2008/2009. UK: NHS, 2010.

34. Blaum CS, Velez L, Hiss RG, et al. Characteristics related to poor glycemic control in NIDDM patients in community practice. Diabetes Care 1997;20:7-11.

35. Benoit SR, Fleming R, Philis-Tsimikas A, et al. Predictors of glycemic control among patients with type 2 diabetes: a longitudinal study. BMC Pub Health 2005;5:36.

36. Taira Juarez D, Sentell T, Tokumaru S, et al. Factors associated with poor glycemic control or wide glycemic variability among diabetes patients in Hawaii, 2006-2009. Prev Chronic Dis 2012;9: E151.

37. Walden CE, Knopp RH, Wahl PW, et al. Sex differences in the effect of diabetes mellitus on lipoprotein triglyceride and cholesterol concentrations. N Engl J Med 1984;311:953-9.

38. Arnetz L, Rajamand Ekberg N, Alvarsson M. Sex differences in type 2 diabetes: focus on disease course and outcomes. Diabetes Metab Syndr Obes 2014;7:409-20.

39. McAllister M, Dunn G, Payne K, et al. Patient empowerment: the need to consider it as a measurable patient-reported outcome for chronic conditions. BMC Health Serv Res 2012;12:157.

40. Anderson RM, Funnell MM, Aikens JE, et al. Evaluating the efficacy of an empowerment-based self-management consultant intervention results of a two-year randomized controlled trial. Ther Patient Educ 2009;1:3-11.

41. Eigenmann CA, Colagiuri R, Skinner TC, et al. Are current psychometric tools suitable for measuring outcomes of diabetes education? Diabet Med 2009;26:425-36.

42. Balanda KP, Buckley CM, Barron SJ, et al. Prevalence of diabetes in the Republic of Ireland: results from the National Health Survey (SLAN) 2007. PLOS ONE 2013;8:e78406.

43. Arnold LW, Wang Z. The HbA1c and all-cause mortality relationship in patients with type 2 diabetes is J-shaped: a meta-analysis of observational studies. Rev Diabet Stud 2014;11:138-52. 